Trunk, M.; Herrmann, A. ; Bildirir, H. ; Yassin, A.; Schmidt, J.; Thomas, A.

\title{
Copper-Free Sonogashira Coupling for High-Surface-Area Conjugated Microporous Poly(aryleneethynylene) Network
}

Journal article | Accepted manuscript (Postprint)

This version is available at https://doi.org/10.14279/depositonce-8302

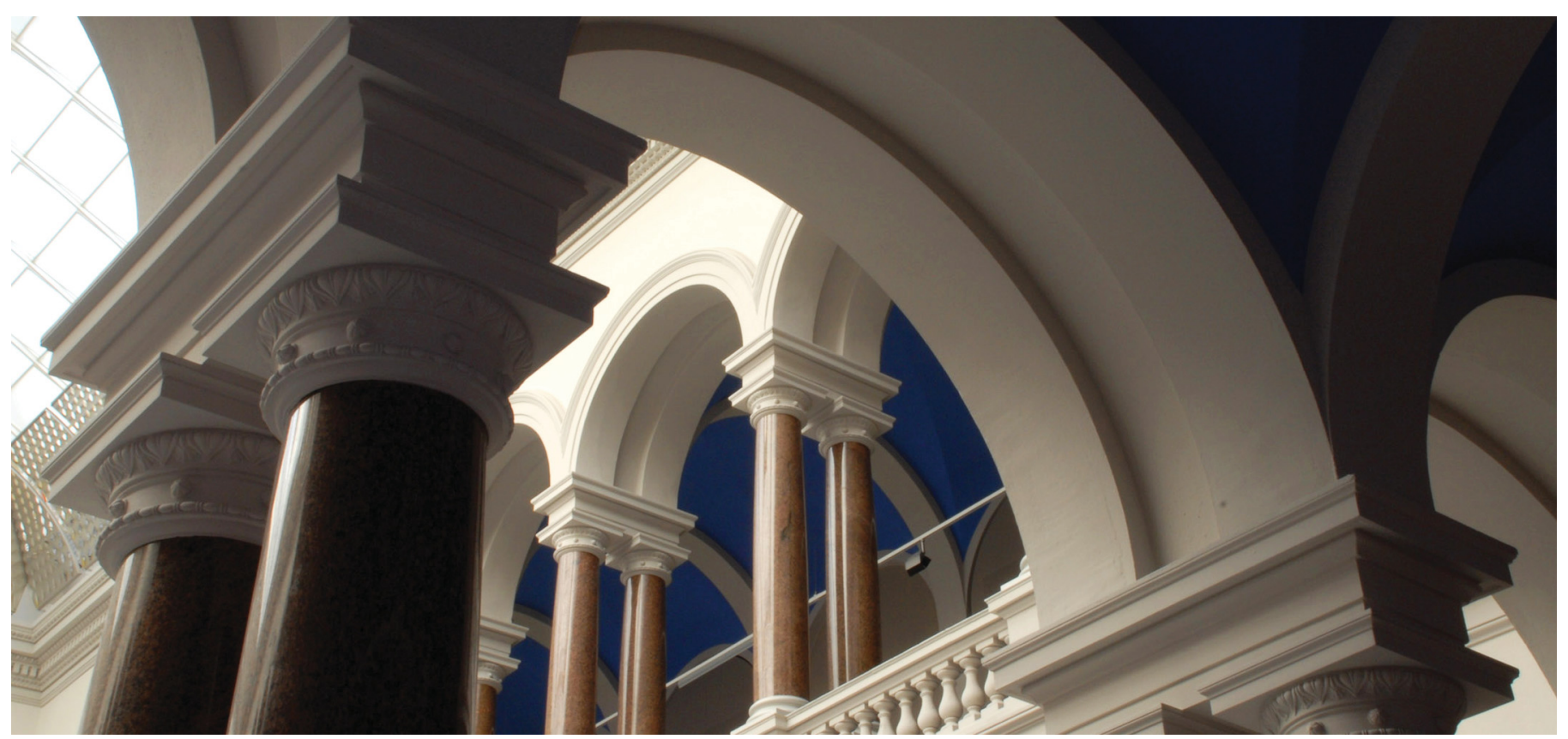

This is the peer-reviewed version of the following article:

Trunk, M., Herrmann, A., Bildirir, H., Yassin, A., Schmidt, J., \& Thomas, A. (2016). Copper-Free Sonogashira Coupling for High-Surface-Area Conjugated Microporous Poly(aryleneethynylene) Networks. Chemistry - A European Journal, 22(21), 7179-7183. https://doi.org/10.1002/chem.201600783,

which has been published in final form at https://doi.org/10.1002/chem.201600783. This article may be used for non-commercial purposes in accordance with Wiley-VCH Terms and Conditions for Self-Archiving. 


\title{
Copper-Free Sonogashira Coupling for High-Surface-Area Conjugated Microporous Poly(aryleneethynylene) Networks
}

\author{
Matthias Trunk, Anna Herrmann, Hakan Bildirir, Ali Yassin, Johannes Schmidt, and \\ Arne Thomas ${ }^{[a]}$
}

\begin{abstract}
A modified one-pot Sonogashira cross-coupling reaction based on a copper-free methodology has been applied for the synthesis of conjugated microporous poly(aryleneethynylene) networks (CMPs) from readily available iodoarylenes and 1,3,5-triethynylbenzene. The polymerization reactions were carried out by using equimolar amounts of halogen and terminal alkyne moieties with extremely small
\end{abstract}

loadings of palladium catalyst as low as $0.65 \mathrm{~mol} \%$. For the first time, CMPs with rigorously controlled structures were obtained without any indications of side reactions, as proven by FTIR and solid-state NMR spectroscopy, while showing Brunauer-Emmett-Teller (BET) surface areas higher than any poly(aryleneethynylene) network reported before, reaching up to $2552 \mathrm{~m}^{2} \mathrm{~g}^{-1}$.

\section{Introduction}

Over the last two decades, microporous organic materials have seen remarkable development due to their potential applications in gas storage, separation, sensing, and catalysis. ${ }^{[1,2]}$ This development has been accelerated by the general trend towards sustainability and a call for less energy-intensive alternatives for industrial procedures, such as cryogenic distillation. Aside from ordered materials, such as metal-organic frameworks (MOFs) ${ }^{[3]}$ and covalent organic frameworks (COFs), ${ }^{[4,5]} \mathrm{mi}-$ croporous polymer networks (MPNs) have emerged as a family of amorphous yet highly promising materials for a range of applications. ${ }^{[6-10]}$ Apart from polymeric materials, porous organic molecules have gained an increasing amount of attention recently. ${ }^{[11-16]}$ Extensive studies have produced unique combinations of high accessible surface areas and chemical robustness, as well as thermal stability, often surpassing MOFs and COFs in those respects, although in exchange for ordered structures. ${ }^{[1,2,17]}$ A plethora of porous polymers has been obtained through a variety of polymerization methods. Especially the palladium-catalyzed procedure following the Sonogashira-type protocol published by Cooper et al. ${ }^{[6]}$ to produce conjugated microporous poly(aryleneethynylene) networks (CMPs) is a commonly employed method to incorporate functional groups into porous polymer backbones. ${ }^{[18]}$ Further functional groups can be grafted onto the polymer backbones postsynthetical-

[a] M. Trunk, A. Herrmann, Dr. H. Bildirir, Dr. A. Yassin, Dr. J. Schmidt, Prof. Dr. A. Thomas

Department of Chemistry, Functional Materials

Technische Universität Berlin

Hardenbergstrasse 40, 10623 Berlin (Germany)

E-mail:arne.thomas@tu-berlin.de ly. ${ }^{[19-21]}$ The importance of these materials is emphasized by the recent commercialization of CMP-1 by Sigma-Aldrich. ${ }^{[22]}$

Since 2007, different protocols for CMP syntheses with varying solvents, temperature, starting materials, and stoichiometry have been reported. ${ }^{[23-26]}$ Initially, ethynyl-functionalized aromatic compounds were reacted with aryl iodides, which were later often succeeded by more readily available bromides, whereby lower degrees of condensation accompanied by slightly lower surface areas were observed. ${ }^{[18,27]}$ Surprisingly and solely based on empirical findings, the highest surface area for a given CMP was obtained by use of a $50 \%$ excess of alkyne functions, which should actually give unreacted alkyne end groups within the resulting network structures, ${ }^{[23]}$ and be detrimental for reaching high surface areas in a MPN. A recent article addresses the issue of this counterintuitive stoichiometry in depth, focusing on the network formation with special attention paid to open end groups within the network. ${ }^{[28]}$ Herein, the empirically found necessity for an excess of ethynyl groups for the formation of high-surface-area materials is rationalized by an ongoing reaction of ethynyl end groups, which are trapped within the precipitated material. These ethynyl groups cross-link during elongated reaction times, whereas halide end groups would remain unreactive after gelation, giving dead ends within the polymer. The steady decrease in terminal ethynyl functions was shown to be accompanied by a rise in nitrogen-accessible surface area. Nevertheless, the use of equimolar monomer ratios can also be found in the literature. ${ }^{[10,24,29,30]}$ Recently, Son and co-workers used the correct stoichiometry to create impressive surface areas of almost $1800 \mathrm{~m}^{2} \mathrm{~g}^{-1}$ by systematic variation of the phosphine ligand accompanying the palladium catalyst. ${ }^{[26]}$

To elucidate the exact formation mechanism and the nature of the homocoupling product, Bunz and co-workers created a homocoupled CMP from a tetrahedral tin-based monomer, which was digested after polymerization. The fragments were 
analyzed to shed light on the structure of the struts linking the former nodes, and thereby on the mechanism of internal crosslinking. The struts were found to consist of isomeric enynes originating from dimers, trimers, and tetramers of alkyne groups. $^{[31]}$

To make the conventional homogeneous Sonogashira coupling less susceptible to oxygen and to prevent the formation of side-products, copper-free variants have been developed, although the copper-free mechanism is yet unknown. ${ }^{[32,33]}$ Motivated by these routes and to avoid the aforementioned sidereactions during CMP formation, we developed a copper-free polymerization method employing the exact stoichiometry of alkyne and halide functions.

From a practical point of view, the addition of the catalyst into the hot reaction mixture in the form of a slurry, as it was reported before, seemed to us unfeasible. ${ }^{[6]}$ Residues of insoluble catalyst remaining inside the syringe, cannula, or the vessel used for the preparation of the slurry can prove detrimental to reproducibility and rinsing aforementioned vessel with solvent makes the reaction prone to oxygen contamination. Thus, the herein presented route was originally developed to provide a facile and robust one-pot procedure, using equimolar amounts of ethynyl and halide groups, thus avoiding side-reactions while keeping the conversion efficiency of functional groups as high as possible.

\section{Results and Discussion}

To understand and perhaps eliminate the empirically found necessity for a large excess of alkyne functionalities, the reaction parameters were optimized for commercial starting materials, 1,4-diiodobenzene and 1,3,5-triethynylbenzene (TEB). However, the first problem for a controlled polymer synthesis was posed by the varying states in which TEB arrives after purchase (Figure $1 \mathrm{a}$ ). Purification of the as-purchased monomer by column chromatography gave a yellow, crystalline powder (Figure 1b). Further investigation showed that the monomer can be purified by a simple sublimation procedure $\left(40^{\circ} \mathrm{C} 10^{-3} \mathrm{mbar}\right)$ to give pristine, colorless crystals, which correspond to the expected appearance (Figure $1 \mathrm{c}$ ).

Storage of the alkyne at $8^{\circ} \mathrm{C}$ showed no evidence of decomposition over several months, whereas elongated exposure to ambient temperature caused the material to turn brown, even when stored under inert conditions. We attribute this behavior to a high inherent reactivity of multi-alkyne compounds, which could in part account for the need of an excess of these compounds when non-purified monomers are applied, because parts of the ethynyl groups have already reacted and thus are not available for further polymerization.

It is a known fact that the use of aryl iodides over bromides facilitates a smoother reaction, which lowers the probability of unreacted end groups. Therefore, iodoarylenes were exclusively used in this study. Upon testing different conditions, it was found

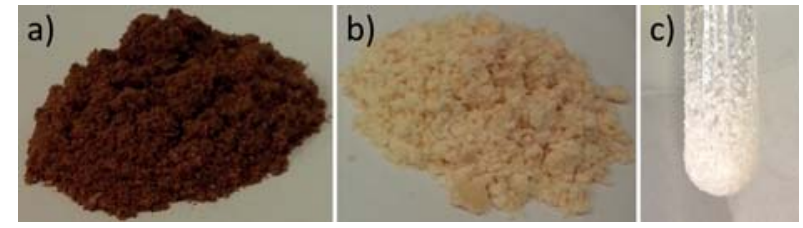

Figure 1. Varying states of 1,3,5-triethynylbenzene: a) as-purchased; b) after column chromatography from dichloromethane; and c) after sublimation.

that for aryl iodides and polyalkynes, high surface areas could be obtained when the amount of palladium catalyst $\left[\mathrm{Pd}\left(\mathrm{PPh}_{3}\right)_{4}\right]$ was reduced to $0.65 \mathrm{~mol} \%$ per iodide/alkyne moiety, whereas the co-catalyst, copper(I) iodide, was omitted completely. ${ }^{[34]}$ Reaction of TEB with 1,3,5-triiodobenzene, 1,4diiodobenzene, 4,4'-diiodobiphenyl, and tetrakis(4-iodophenyl)methane in a mixture of DMF/NEt $\mathrm{N}_{3}$ (2:1) gave highly electrostatic, spongy materials P1-P4 (Scheme 1). The resultant powders range from off-white to yellow, according to the length and geometry of the conjugated system. Materials P1 and P4, consisting only of weakly electronically conjugated 1,3-connected aromatics, were obtained as beige and off-white, respectively. In contrast, polymers emerging from 1,4-functionalised arylenes form longer conjugated aromatic systems, giving rise to different hues of yellow (P2 and P3). It should be noted that materials with structures similar to these materials are described in literature-P1 corresponds to $\mathrm{CMP}^{-\mathrm{X}_{1}^{[24]}} \mathbf{P} \mathbf{2}$ and $\mathbf{P} \mathbf{3}$ correspond to CMP-1 and $-2,{ }_{,}^{[6]}$ respectively, and a structure similar to P4 was also reported. ${ }^{[35]}$

However, not only are the materials reported herein much closer to their ideal structures, but they also exhibit significantly enhanced BET surface areas. Furthermore, P1-P4 are fluorescent under UV light ( $\lambda=254 \mathrm{~nm}$, light fluorescence; $366 \mathrm{~nm}$,

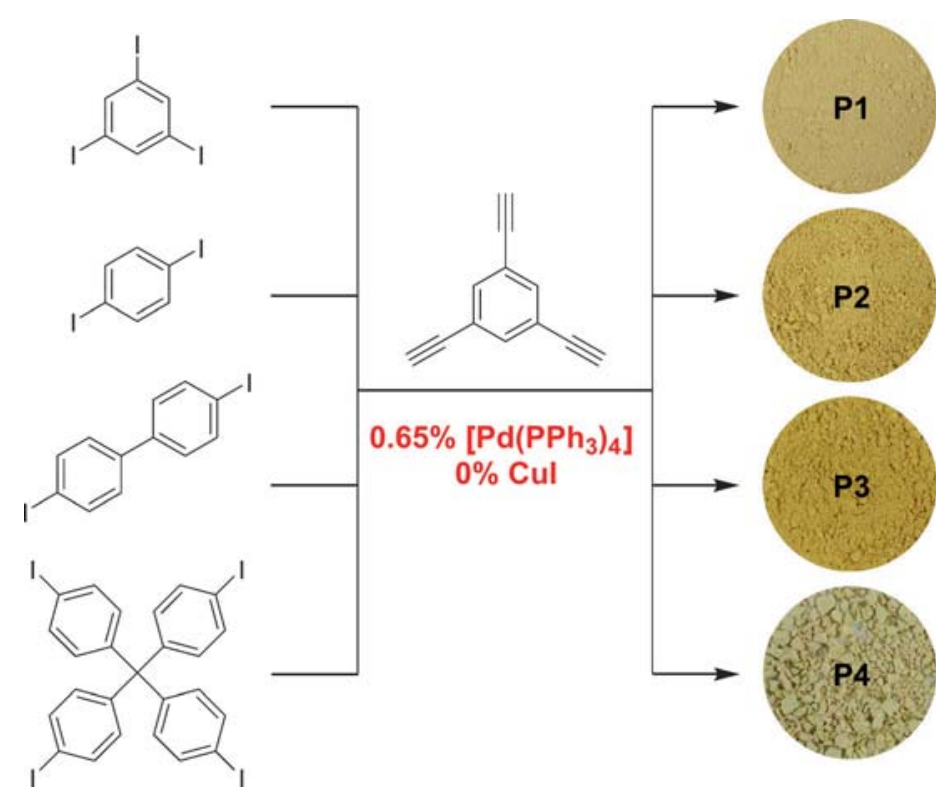

Scheme 1. Copper-free synthetic procedure towards CMPs based on 1,3,5-triethynylbenzene. All reactions were carried out in a mixture of dimethylformamide/triethylamine (2:1) at $100^{\circ} \mathrm{C}$ for $20 \mathrm{~h}$. 
strong fluorescence), whereas reproduced CMP-1 was found to be non-fluorescent.

Compound P1 was synthesized by reaction of TEB with 1,3,5-triiodobenzene. According to its highly symmetrical (ideal) structure, P1 exhibits three major peaks at $\delta=131,121$, and $86 \mathrm{ppm}$ in the ${ }^{13} \mathrm{C} \mathrm{CP/MAS} \mathrm{NMR} \mathrm{spectrum} \mathrm{(Figure} \mathrm{2).}$

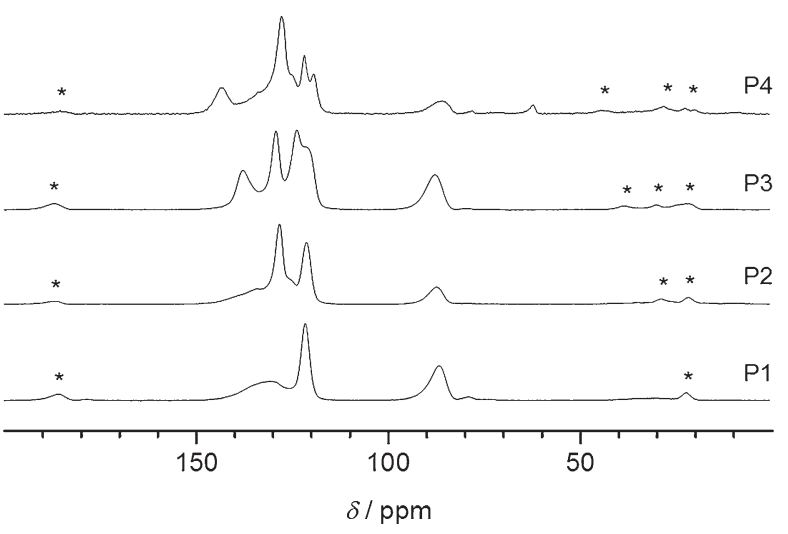

Figure 2. ${ }^{13} \mathrm{C}$ NMR spectra of P1-P4; asterisks $\left({ }^{*}\right)$ denote spinning sidebands.

These peaks can be unambiguously assigned to $C_{\mathrm{Ar}}-\mathrm{H}$ (130$133 \mathrm{ppm}$, very broad), the quaternary carbon atom $\mathrm{C}_{\mathrm{Ar}}-\mathrm{C} \equiv \mathrm{C}$ (121 ppm), and the acetylenic carbon atoms $C \equiv C(86 \mathrm{ppm})$. Compounds P2, P3, and P4 were synthesized by reaction of TEB with 1,4-diiodobenzene, 4,4'-diiodobiphenyl, and tetrakis(4-iodophenyl)methane, respectively. As can be seen, the peak positions of the triethynylbenzene motif in P2, P3, and P4 are largely unchanged from that in P1 (Figure 2, dashed lines). All remaining peaks of $\mathbf{P} \mathbf{2}, \mathbf{P} \mathbf{3}$, and $\mathbf{P} \mathbf{4}$ can be assigned accordingly (see the Supporting Information). Additionally, for P1 and P4, small amounts of unreacted alkyne groups were found at $\delta=78$ ppm.

The high conversion efficiency of this method was confirmed by FTIR measurements (Figure 3). Comparison of the

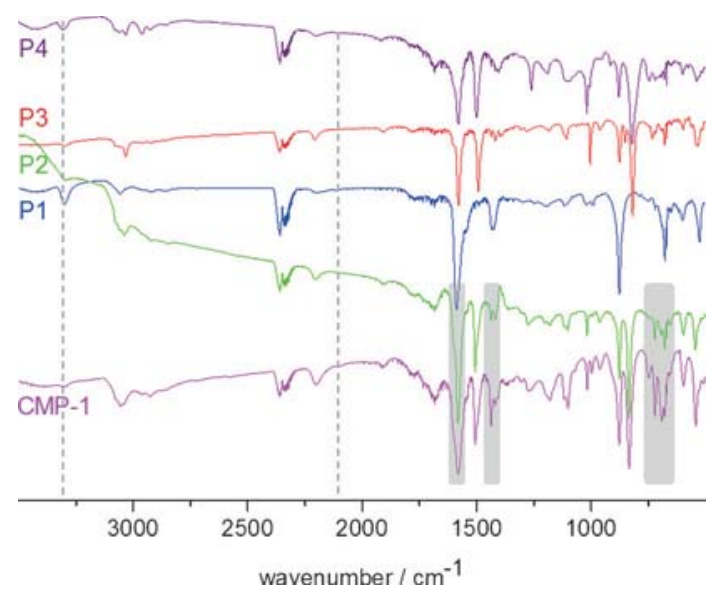

Figure 3. FTIR spectra of P1 (blue), P2 (green), P3 (red), and P4 (purple) exhibiting very low concentrations of terminal alkyne moieties (2100 and $3300 \mathrm{~cm}^{-1}$, dashed lines), and conventional CMP-1 (pink). Structural differences between CMP-1 and P2 are highlighted (shaded insets). peak intensities for internal alkynes $\left(2200 \mathrm{~cm}^{-1}\right)$ and terminal alkynes (2100 and $3300 \mathrm{~cm}^{-1}$, dashed lines) showed low concentrations of terminal alkyne moieties for P1 and P4, and traces for $\mathbf{P 2}$ and $\mathbf{P 3}$, which is in good agreement with the NMR data. Furthermore, structural differences between P2 and CMP-1, prepared by the conventional method by hot injection under excess of TEB, can be observed (Figure 3, shaded insets). The occurrence of a shoulder at $1600 \mathrm{~cm}^{-1}$ and the additional band at $1440 \mathrm{~cm}^{-1}$ in the CMP-1 spectrum resulted from the formation of enyne moieties, which is in agreement with IR data reported before ${ }^{[36]}$ and the NMR data acquired by Bunz and co-workers. ${ }^{[31]}$

These enyne groups are the product of coupling of the remaining terminal alkyne groups, which can therefore no longer be observed for CMP-1, despite the huge excess of TEB employed in the synthesis. Further differences can be observed in the fingerprint region around $700 \mathrm{~cm}^{-1}$.

As was pointed out previously, the same network structure as P1 has been reported before. ${ }^{[2]}$ However, the previous solid-state ${ }^{13} \mathrm{C}$ NMR spectrum exhibited an additional sharp peak at $\delta=131 \mathrm{ppm}$, which we attribute to only partially consumed starting material due to non-optimal reaction conditions and less reactive 1,3,5-tribromobenzene. Consequently, the resulting network would exhibit a lower degree of conversion. Testament to this assumption are the comparatively low reported surface areas, which lie in the range of 370 to $400 \mathrm{~m}^{2} \mathrm{~g}^{-1}$, whereas for P1 a surface area of $914 \mathrm{~m}^{2} \mathrm{~g}^{-1}$ was detected. For P2 and P3, 1720 and $873 \mathrm{~m}^{2} \mathrm{~g}^{-1}$ were obtained (Figure 4). These values surpass the surface areas of structurally

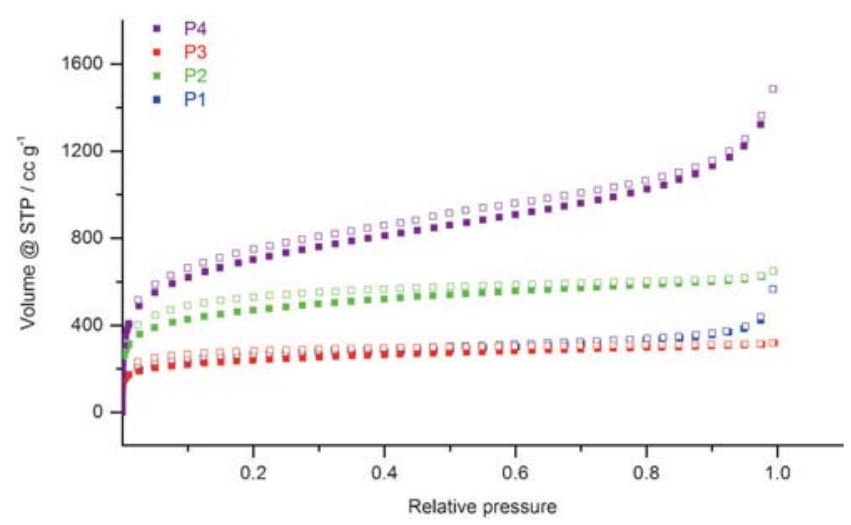

Figure 4. $\mathrm{N}_{2}$ uptake at $77 \mathrm{~K}$ for P1 (blue), P2 (green), P3 (red), and P4 (purple).

related materials obtained by the conventional method of $834 \mathrm{~m}^{2} \mathrm{~g}^{-1}$ for CMP-1 and $634 \mathrm{~m}^{2} \mathrm{~g}^{-1}$ for CMP-2 (Table 1). The most significant surface-area enhancement was found for P4, which exhibited an impressive surface area of $2552 \mathrm{~m}^{2} \mathrm{~g}^{-1}$. This equals more than five times the accessible surface area of the structurally related material published previously, ${ }^{[35]}$ and is the highest BET surface area of any poly(aryleneethynylene) network reported to date, surpassing even those formed by dynamic alkyne metathesis. ${ }^{[10]}$ 


\begin{tabular}{|c|c|c|c|c|}
\hline & $\begin{array}{l}S_{\text {BET }} \text { (reported) } \\
{\left[\mathrm{m}^{2} \mathrm{~g}^{-1}\right]}\end{array}$ & $\begin{array}{l}S_{\text {BET }} \text { (this work) } \\
{\left[\mathrm{m}^{2} \mathrm{~g}^{-1}\right]}\end{array}$ & $\begin{array}{l}\mathrm{CO}_{2} \text { uptake } \\
{\left[\mathrm{mmol} \mathrm{g}^{-1}\right]^{[a]}}\end{array}$ & $\begin{array}{l}\mathrm{H}_{2} \text { uptake } \\
{[\mathrm{wt} \%]^{[b]}}\end{array}$ \\
\hline $\mathrm{P} 1 / \mathrm{CMP}^{-\mathrm{X}^{[24]}}$ & 397 & 914 & 3.01 & 1.32 \\
\hline $\mathrm{P} 2 / \mathrm{CMP}-\mathbf{1}^{[6]}$ & 834 & 1720 & 2.53 & 1.36 \\
\hline $\mathrm{P} 3 / \mathrm{CMP}^{-2^{[6]}}$ & 634 & 873 & 2.12 & 1.00 \\
\hline $\mathbf{P} 4 / \mathrm{E2}^{[35]}$ & 488 & 2552 & 3.36 & 1.59 \\
\hline
\end{tabular}

The high accessible surface area of P4 also gives rise to considerable sorption capacity towards other gases; the total uptake values for $\mathrm{H}_{2}$ at $77 \mathrm{~K}$ and 1 bar, as well as for $\mathrm{CO}_{2}$ at $273 \mathrm{~K}$ and $1 \mathrm{bar}$ are among the highest reported for as-synthesized MPNs. ${ }^{[2,37]}$ Especially the almost linear shape of the $\mathrm{CO}_{2}$ adsorption curve suggests remarkable uptake under high pressure (see the Supporting Information).

In compounds P1-P3, two dominant pore sizes around 0.6 and $0.9 \mathrm{~nm}$ were found according to non-local (NL) DFT calculations derived from the nitrogen-sorption measurements (Figure 5). A decrease in the relative intensity of the smaller pores is accompanied by an increase in surface area. The same tendency was reported previously ${ }^{[26]}$ and culminates in $\mathbf{P 4}$ for which pores at $1.10 \mathrm{~nm}$ were observed exclusively, and which has the highest BET surface area.

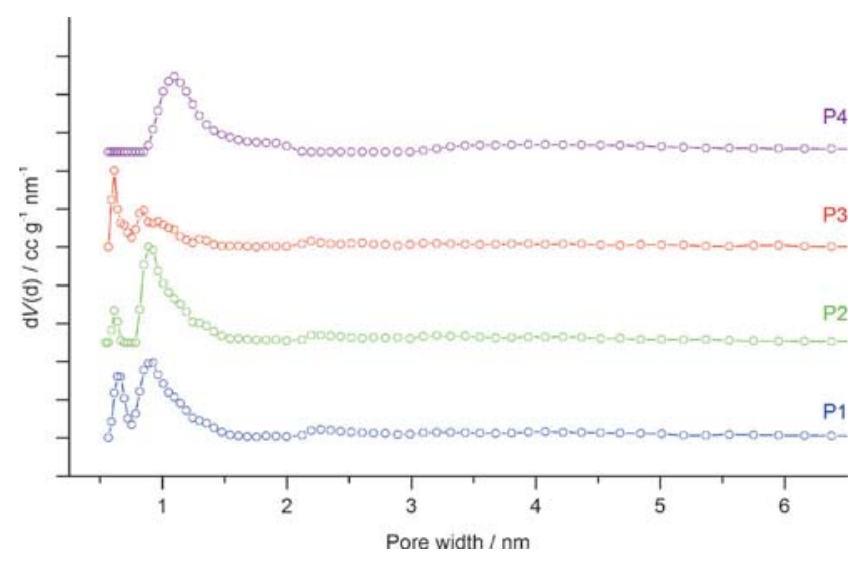

Figure 5. Pore-size distributions of P1 (blue), P2 (green), P3 (red), and P4 (purple).

\section{Conclusion}

We herein present an improved protocol for the synthesis of conjugated microporous polymers based on the Sonogashira cross-coupling reaction. Experiments were carried out in a facile one-pot procedure, and the amounts of halide and alkyne groups were adjusted to $1: 1$. By reduction of the amount of palladium catalyst to $0.65 \mathrm{~mol} \%$ and removal of the co-catalyst, copper(I) iodide, for the first time, CMPs with rigorously controlled chemical structure and high BET surface areas of up to $2552 \mathrm{~m}^{2} \mathrm{~g}^{-1}$ were obtained. We will continue to gain further mechanistic insights into the polymerization reaction and widen the applicability of this facile and highly efficient synthesis protocol.

\section{Experimental Section}

Materials: All chemicals were used as received unless otherwise noted. Tetrakis(4-iodophenyl)methane and 1,3,5-triiodobenzene were synthesized according to a literature procedure with slight modifications (see the Supporting Information). 1,3,5-Triethynylbenzene was purchased from $\mathrm{TCl}$ and sublimated before use ( $40^{\circ} \mathrm{C} 10^{-3} \mathrm{mbar}$ ). Tetrakis(triphenylphosphine)palladium(0) (99.9\%), 1,4-diiodobenzene (99\%), 1,3,5-tribromobenzene ( $98 \%)$, anhydrous tetrachloromethane $(\geq 99.5 \%)$, anhydrous dimethylformamide $(99.8 \%)$, and triethylamine $(\geq 99.5 \%)$ were purchased from SigmaAldrich. 4,4'-Diiodobiphenyl (99\%) was purchased from Alfa Aesar. Bis(trifluoroacetoxy)iodobenzene (98\%) and iodine (99.5\%) were purchased from Acros Organics. Tetraphenylmethane (96\%) was purchased from Manchester Organics.

Synthetic procedure for P1: Inside the glovebox, a $50 \mathrm{~mL}$ glass vial was charged with 1,3,5-triethynylbenzene (100.6 mg, $670 \mu \mathrm{mol}), 1,3,5$-triiodobenzene $(305.4 \mathrm{mg}, 670 \mu \mathrm{mol}),\left[\mathrm{Pd}\left(\mathrm{PPh}_{3}\right)_{4}\right]$ $(15.1 \mathrm{mg}, 13 \mu \mathrm{mol})$, dimethylformamide $(12 \mathrm{~mL})$, and triethylamine $(6 \mathrm{~mL})$. The vessel was closed with a silicone septum, extracted from the glovebox, and immersed in an oil bath preheated to $100^{\circ} \mathrm{C}$. The colorless solution turned increasingly yellow, and a voluminous pale yellow precipitate formed after several minutes. The mixture was kept at $100^{\circ} \mathrm{C}$ for $20 \mathrm{~h}$, quenched by addition of methanol, and filtered. The resulting beige solid was purified by Soxhlet extraction from methanol overnight and dried in the vacuum oven at $80^{\circ} \mathrm{C}$ overnight.

Synthetic procedure for P2: Inside the glovebox, a $5 \mathrm{~mL}$ glass vial was charged with 1,3,5-triethynylbenzene $(100.1 \mathrm{mg}, 667 \mu \mathrm{mol})$, 1,4-diiodobenzene $(329.9 \mathrm{mg}, 1.00 \mathrm{mmol}),\left[\mathrm{Pd}\left(\mathrm{PPh}_{3}\right)_{4}\right] \quad(7.5 \mathrm{mg}$, $6.5 \mu \mathrm{mol})$, dimethylformamide $(3 \mathrm{~mL})$, and triethylamine $(1.5 \mathrm{~mL})$. The vessel was closed with a silicone septum, extracted from the glovebox, and immersed in an oil bath preheated to $100^{\circ} \mathrm{C}$. The colorless solution turned increasingly yellow, and a voluminous yellow precipitate formed after several minutes. The mixture was kept at $100^{\circ} \mathrm{C}$ for $20 \mathrm{~h}$, quenched by addition of methanol, and filtered. The resulting yellow solid was purified by Soxhlet extraction from methanol overnight and dried in the vacuum oven at $80^{\circ} \mathrm{C}$ overnight.

Synthetic procedure for P3: Inside the glovebox, a $50 \mathrm{~mL}$ glass vial was charged with 1,3,5-triethynylbenzene (100.3 mg, $668 \mu \mathrm{mol}), 4,4^{\prime}$-diiodobiphenyl (406.7 mg, $\left.1.00 \mathrm{mmol}\right),\left[\mathrm{Pd}\left(\mathrm{PPh}_{3}\right)_{4}\right]$ $(15.1 \mathrm{mg}, 13 \mu \mathrm{mol})$, dimethylformamide $(12 \mathrm{~mL})$, and triethylamine $(6 \mathrm{~mL})$. The vessel was closed with a silicone septum, extracted from the glovebox, and immersed in an oil bath preheated to $100^{\circ} \mathrm{C}$. The colorless solution turned increasingly yellow, and a voluminous yellow precipitate formed after several minutes. The mixture was kept at $100^{\circ} \mathrm{C}$ for $20 \mathrm{~h}$, quenched by addition of methanol, and filtered. The resulting yellow solid was purified by Soxhlet extraction from methanol overnight and dried in the vacuum oven at $80^{\circ} \mathrm{C}$ overnight.

Synthetic procedure for P4: Inside the glovebox, a $50 \mathrm{~mL}$ glass vial was charged with 1,3,5-triethynylbenzene ( $20.1 \mathrm{mg}, 134 \mu \mathrm{mol})$, tetrakis(4-iodophenyl)methane $(82.8 \mathrm{mg}, 101 \mu \mathrm{mol}), \quad\left[\mathrm{Pd}\left(\mathrm{PPh}_{3}\right)_{4}\right]$ $(3.1 \mathrm{mg}, 2.7 \mu \mathrm{mol})$, dimethylformamide $(24 \mathrm{~mL})$, and triethylamine $(12 \mathrm{~mL})$. The vessel was closed with a silicone septum, extracted from the glovebox, and immersed in an oil bath preheated to $100^{\circ} \mathrm{C}$. The colorless solution turned increasingly yellow, and a volu- 
minous pale yellow precipitate formed after several minutes. The mixture was kept at $100^{\circ} \mathrm{C}$ for $20 \mathrm{~h}$, quenched by addition of methanol, and filtered off. The resulting off-white solid was purified by Soxhlet extraction from methanol overnight and dried in the vacuum oven at $80^{\circ} \mathrm{C}$ overnight.

Synthetic procedure for reproduced CMP-1: Inside the glovebox, $\left[\mathrm{Pd}\left(\mathrm{PPh}_{3}\right)_{4}\right](50.1 \mathrm{mg}, 43 \mu \mathrm{mol})$ and Cul $(15.0 \mathrm{mg}, 79 \mu \mathrm{mol})$ were suspended in dimethylformamide $(1.5 \mathrm{~mL})$ and taken up into a syringe. A $5 \mathrm{~mL}$ glass vial was charged with 1,3,5-triethynylbenzene (150.2 $\mathrm{mg}, 1.00 \mathrm{mmol}), 1$,4-diiodobenzene $(330.0 \mathrm{mg}, 1.00 \mathrm{mmol})$, dimethylformamide $(1.5 \mathrm{~mL})$, and triethylamine $(1.5 \mathrm{~mL})$. The vessel was equipped with a silicone septum and a balloon, the vial and syringe were extracted from the glovebox, and the vial was immersed in an oil bath preheated to $100^{\circ} \mathrm{C}$. After $5 \mathrm{~min}$, the catalyst mixture was added into to the vial through the septum. The colorless solution turned yellow instantly, and a brown precipitate formed after a few seconds. The mixture was kept at $100^{\circ} \mathrm{C}$ for $20 \mathrm{~h}$, quenched by addition of methanol, and filtered. The resulting brown solid was purified by Soxhlet extraction from methanol overnight and dried in the vacuum oven at $80^{\circ} \mathrm{C}$ overnight.

Further experimental and analytical data are given in the Supporting Information.

\section{Acknowledgements}

This work was funded by the ERC Project ORGZEO (Grant-Nr.: 278593) and the DFG (Cluster of Excellence UniCat). We thank Christina Eichenauer, Maria Unterweger, and Caren Göbel for the sorption experiments, XRD measurements, and TEM and EDX measurements, respectively.

Keywords: $\mathrm{CO}_{2}$ sorption - conjugated microporous polymers copper-free Sonogashira - covalent organic frameworks hydrogen storage

[1] A. Thomas, Angew. Chem. Int. Ed. 2010, 49, 8328-8344; Angew. Chem. 2010, 122, 8506-8523.

[2] R. Dawson, A. I. Cooper, D. J. Adams, Prog. Polym. Sci. 2012, 37, $530-$ 563.

[3] O. M. Yaghi, G. Li, H. Li, Nature 1995, 378, 703-706.

[4] A. P. Côté, A. I. Benin, N. W. Ockwig, M. O’Keeffe, A. J. Matzger, O. M. Yaghi, Science 2005, 310, 1166-1170.

[5] P. Kuhn, M. Antonietti, A. Thomas, Angew. Chem. Int. Ed. 2008, 47, 3450-3453; Angew. Chem. 2008, 120, 3499-3502.

[6] J.-X. Jiang, F. Su, A. Trewin, C. D. Wood, N. L. Campbell, H. Niu, C. Dickinson, A. Y. Ganin, M. J. Rosseinsky, Y. Z. Khimyak, A. I. Cooper, Angew. Chem. Int. Ed. 2007, 46, 8574-8578; Angew. Chem. 2007, 119, 87288732.

[7] T. Ben, H. Ren, S. Ma, D. Cao, J. Lan, X. Jing, W. Wang, J. Xu, F. Deng, J. M. Simmons, Angew. Chem. Int. Ed. 2009, 48, 9457-9460; Angew. Chem. 2009, 121, 9621-9624.

[8] J. Schmidt, M. Werner, A. Thomas, Macromolecules 2009, 42, 4426 4429.
[9] S. Fischer, J. Schmidt, P. Strauch, A. Thomas, Angew. Chem. Int. Ed. 2013. 52, 12174-12178; Angew. Chem. 2013, 125, 12396-12400.

[10] Y. Zhu, H. Yang, Y. Jin, W. Zhang, Chem. Mater. 2013, 25, 3718-3723.

[11] T. Tozawa, J. T. Jones, S. I. Swamy, S. Jiang, D. J. Adams, S. Shakespeare, R. Clowes, D. Bradshaw, T. Hasell, S. Y. Chong, Nat. Mater. 2009, 8, $973-$ 978.

[12] T. Hasell, S. Y. Chong, K. E. Jelfs, D. J. Adams, A. I. Cooper, J. Am. Chem. Soc. 2012, 134, 588-598.

[13] G. Zhang, O. Presly, F. White, I. M. Oppel, M. Mastalerz, Angew. Chem. Int. Ed. 2014, 53, 1516-1520; Angew. Chem. 2014, 126, 1542-1546.

[14] S. M. Elbert, F. Rominger, M. Mastalerz, Chemistry 2014, 20, 1670716720.

[15] T. Mitra, K. E. Jelfs, M. Schmidtmann, A. Ahmed, S. Y. Chong, D. J. Adams, A. I. Cooper, Nat. Chem. 2013, 5, 276-281.

[16] N. Giri, M. G. Del Pópolo, G. Melaugh, R. L. Greenaway, K. Rätzke, T. Koschine, L. Pison, M. F. C. Gomes, A. I. Cooper, S. L. James, Nature 2015, $527,216-220$.

[17] U. H. F. Bunz, K. Seehafer, F. L. Geyer, M. Bender, I. Braun, E. Smarsly, J. Freudenberg, Macromol. Rapid Commun. 2014, 35, 1466-1496.

[18] R. Dawson, A. Laybourn, R. Clowes, Y. Z. Khimyak, D. J. Adams, A.I. Cooper, Macromolecules 2009, 42, 8809-8816.

[19] W. Lu, D. Yuan, J. Sculley, D. Zhao, R. Krishna, H.-C. Zhou, J. Am. Chem. Soc. 2011, 133, 18126-18129.

[20] Z. Xiang, D. Cao, W. Wang, W. Yang, B. Han, J. Lu, J. Phys. Chem. C 2012 $116,5974-5980$

[21] B. Kiskan, J. Weber, ACS Macro Lett. 2012, 1, 37-40.

[22] Commercial CMP-1 from Sigma Aldrich," can be found under http:// www.sigmaaldrich.com/catalog/product/aldrich/799491?lang=de\&region $=\mathrm{DE}$.

[23] R. Dawson, A. Laybourn, Y. Z. Khimyak, D. J. Adams, A. I. Cooper, Macromolecules 2010, 43, 8524-8530.

[24] D. Tan, W. Fan, W. Xiong, H. Sun, Y. Cheng, X. Liu, C. Meng, A. Li, W.-Q. Deng, Macromol. Chem. Phys. 2012, 213, 1435-1440.

[25] R. Dawson, D. J. Adams, A. I. Cooper, Chem. Sci. 2011, 2, 1173-1177.

[26] B. Kim, N. Park, S. M. Lee, H. J. Kim, S. U. Son, Polym. Chem. 2015, 6, $7363-7367$.

[27] J. Jiang, F. Su, A. Trewin, C. D. Wood, H. Niu, J. T. A. Jones, Y. Z. Khimyak, A. I. Cooper, J. Am. Chem. Soc. 2008, 130, 7710-7720.

[28] A. Laybourn, R. Dawson, R. Clowes, T. Hasell, A. I. Cooper, Y. Z. Khimyak, D. J. Adams, Polym. Chem. 2014, 5, 6325-6333.

[29] D. Tan, W. Xiong, H. Sun, Z. Zhang, W. Ma, C. Meng, W. Fan, A. Li, Microporous Mesoporous Mater. 2013, 176, 25-30.

[30] H. Bildirir, J. P. Paraknowitsch, A. Thomas, Chem. Eur. J. 2014, 20, $9543-$ 9548.

[31] A. C. Uptmoor, J. Freudenberg, S. T. Schwäbel, F. Paulus, F. Rominger, F. Hinkel, U. H. F. Bunz, Angew. Chem. Int. Ed. 2015, 54, 14673-14676.

[32] U. H. F. Bunz, Chem. Rev. 2000, 100, 1605-1644.

[33] R. Chinchilla, C. Nájera, Chem. Soc. Rev. 2011, 40, 5084.

[34] J. N. Wilson, S. M. Waybright, K. McAlpine, U. H. F. Bunz, Macromolecules 2002, 35, 3799-3800.

[35] E. Stöckel, X. Wu, A. Trewin, C. D. Wood, R. Clowes, N. L. Campbell, J. T. Jones, Y. Z. Khimyak, D. J. Adams, A. I. Cooper, Chem. Commun. 2009, 212-214.

[36] N. Kakusawa, K. Yamaguchi, J. Kurita, J. Organomet. Chem. 2005, 690, $2956-2966$.

[37] R. Dawson, A. I. Cooper, D. J. Adams, Polym. Int. 2013, 62, 345-352. 